\title{
Working toward equitable research practices: the value of highlighting complexity and respecting context
}

\author{
Christina Siry $^{1} \cdot$ Sara E. D. Wilmes ${ }^{1}$
}

Received: 2 May 2020 / Accepted: 2 May 2020 / Published online: 16 June 2020

(C) The Author(s) 2020

\begin{abstract}
In this response paper, we reflect upon the contributions of Gallard Martínez, Pitts, Brkich, and Ramos de Robles (this issue) in their manuscript "How does one recognize contextual mitigating factors (CMFs) as a basis to understand and arrive at better approaches to research designs" and elaborate the ways in which we work toward highlighting the contextual complexities within our own research. Our research focuses on working toward equitable practices for culturally and linguistically diverse children in science education, in order to draw on the many cultural and communicative resources they bring to primary school science investigations. We draw upon our previous and current research projects in this forum contribution to tease-apart CMFs related to issues of equity in teaching science with culturally and linguistically diverse primary school children in our national context in Luxembourg. We conclude with a consideration of how the process of unpacking a diverse array of CMFs relative to our work with students helps us select and employ theoretical lenses and research methodologies that position us to gather rich understandings of the complexities within our research contexts and in our work with children and teachers.
\end{abstract}

Keywords Context · Culturally and linguistically diverse (CLD) students · Participatory research $\cdot$ Transformative research $\cdot$ Resource rich

Lead Editor: K. Tobin.

This review essay addresses issues raised in Alejandro José Gallard Martínez, Wesley Pitts, Katie Milton Brkich and S. Lizette Ramos de Robles paper entitled: "How does one recognize contextual mitigating factors (CMFs) as a basis to understand and arrive at better approaches to research designs". https://doi.org/10.1007/s11422-018-9872-2.

Christina Siry

christina.siry@uni.lu

1 Institute for Teaching and Learning, The University of Luxembourg, Esch-sur-Alzette, Luxembourg 


\section{Zusammenfassung}

In diesem Kommentar befassen wir uns mit dem Beitrag von Gallard Martínez, Pitts, Brkich und Ramos de Robles (in dieser Ausgabe) mit dem Titel "How does one recognise contextual mitigating factors (CMFs) as a basis to understand and arrive to better approaches to research designs" und erläutern, wie wir mit diesen kontextabhängigen Komplexitäten innerhalb unserer eigenen Forschung umgehen. Unsere Forschung konzentriert sich darauf, auf Praktiken im naturwissenschaftlichen Unterricht hinzuarbeiten, die der kulturellen und sprachlichen Vielfältigkeit der Kinder gerecht werden - mit dem Ziel, auf die vielen kulturellen und kommunikativen Ressourcen zurückzugreifen, die Kinder in die naturwissenschaftlichen Untersuchungen in der Grundschule einbringen.

Unsere Forschung ist in Luxemburg verortet, einem Land mit einer Einwandererbevölkerung von fast 50\% und mehr als 170 verschiedenen Nationalitäten (STATEC 2018). In den letzten 25 Jahren erlebte Luxemburg "den höchsten anhaltenden Zustrom von Einwanderern im Verhältnis zur Gesamtbevölkerung" in Europa (Eurydice 2004, deutsche Übersetzung durch die Verfasserinnen). Da die Vielfalt des Landes auch in den Schulen vertreten ist und 46\% der Schülerinnen und Schüler nicht-luxemburgische Staatsangehörige sind (MENJE 2019), befinden sich in vielen Klassen Kinder, die sich einer Vielzahl an kommunikativen Ressourcen bedienen, während sie gleichzeitig die Unterrichtssprache(n) erst noch lernen.

In diesem Kommentar greifen wir auf unsere früheren und aktuellen Forschungsprojekte zurück, um die CMFs in Bezug auf Fragen der Gleichberechtigung im Naturwissenschaftsunterricht von kulturell und sprachlich unterschiedlichen Grundschulkindern in unserem nationalen Kontext in Luxemburg zu identifizieren. Ausgehend von der Erkenntnis, dass die in der Forschung verwendeten Theorien und Methoden sowohl das Offensichtliche als auch das Verdeckte prägen (Tobin 2008), arbeiten wir die Rolle des Kontexts durch den theoretischen Blickwinkel heraus, den wir in unserer eigenen Forschung einsetzen. In einem nächten Schritt bauen wir auf der Arbeit von Gallard Martínez et al. auf, indem wir die Komplexität unserer eigenen Forschungskontexte erörtern und anschließend die Rolle des Kontextverständnisses bei der Arbeit an transformativer Forschung reflektierend untersuchen. Wir schließen mit einer Überlegung darüber, wie der Prozess der Identifizierung eines vielfältigen Spektrums von CMFs in Bezug auf unsere Arbeit mit Studierenden uns hilft, theoretische Perspektiven und Forschungsmethoden auszuwählen und anzuwenden, die uns in die Lage versetzen, differenzierte Erkenntnisse über die Komplexität innerhalb unserer Forschungskontexte und in unserer Arbeit mit Kindern und Lehrpersonen zu sammeln.

In their paper, How does one recognize contextual mitigating factors (CMFs) as a basis to understand and arrive at better approaches to research designs (this issue), Alejandro José Gallard Martínez, Wesley Pitts, Katie Milton Brkich, and S. Lizette Ramos de Robles elaborate an approach for recognizing the myriad, intertwining factors at play in a given research context. They present an analytic concept for conducting research, that "has at its foundation the criticalness of understanding that sociocultural, -economical, -historical, -political contexts shape and influence the understanding of data" and they elaborate further that the concept of CMFs represents "a continuous set of socio-historical-political contextual constructs which are fluid and dynamic, simultaneously interweaving community, education, family, gender/identity, and other socially constructed domains." CMFs 
are continuously in flux and are described by the authors as being the "socially connective tissue when contextualized within a system." Educational systems are highly complex, and there are many contextualized factors that work together to position an individual, and in doing so they come together across various grain sizes to mediate a person's success. Thus, understanding the factors that can mitigate the positionality of an individual is, in our perspective, critical for working toward equity and reform, and for working with participants of research to raise awareness of their own positionalities. In this response paper, we extend the conversation begun by Gallard Martínez et al., as we reflect upon the role of context in educational research, consider the role of complexity and difference relative to context, and advocate for paying attention to context as a means of working toward transformation; whether it be transformation of the individual, of the group, of the context itself, or of the entire system.

Gallard Martínez et al., bring to the forefront a critical issue for consideration in the design and consumption of research, as they elaborate the necessity of recognizing the dynamics in socio-historical-cultural-political contexts. Their work highlights the value of working toward recognizing the constellation of factors that work together to position individuals, including income, gender, race, ethnicity, language ability, and age. Reflecting upon their paper underscores the immense complexity of educational contexts, and indeed, of life in general, and the inherent challenges of trying to understand another's experiences, perspectives, and positioning. While we believe we can never uncover and understand all of this, complex systems thinking provides a way to position CMFs in order to recognize situated phenomena and identify the CMFs that are relevant for understanding research, with the goal of working toward agency and equity. Starting from an understanding that the theories and methodologies used in research shape what is revealed, as well as what is obscured (Tobin 2008), in the sections that follow we elaborate the role of context through the theoretical lenses we employ in our own research. Next, we build upon the work of Gallard Martínez et al., with a discussion of the complexity of our own research contexts and follow this with a reflective exploration of the role of understanding context when working toward transformative research.

\section{Putting "context" into context}

In 1985, the journal Research in Science Education published an article by Richard White, in which he elaborated on the potentials for a new revolution in science education; one that he saw as having been "overlooked by theorists as well as researchers." The factor that he claimed has a great potential for promoting revolution in our field is context. Unfortunately, 35 years later, we have yet to see this revolution in science education on a large scale. Results of research are often discussed as if they are "contextfree," or when mentioned, contextual factors are presented in thin slices, as glimmers of information which take a back-seat relative to findings. But, before we reflect upon why this "revolution" has not taken place, perhaps first we need to reflect about what we even mean by the term context, and why context is important to our research and practice. In the sections that follow, we introduce and elaborate our perspectives on context relative to science education research and practice, and we connect back to the work of Gallard Martínez et al. (this issue). We hope that doing so provides new points for considering the ways in which context shapes individuals' positionings and that a reader can reflect upon these perspectives as relative to their own work. Perhaps in shining a 
light on context and contextually mitigating factors, we can work as a field toward the revolution that White called us to in 1985 .

\section{Context as inter-related conditions}

The interconnectedness of social and cultural factors within the social sciences necessitates an understanding of the inter-related conditions that are occurring; in short, an understanding of the context. But, how do we work toward representing and understanding context? Can we even ever truly understand the contextual complexities of a given place and situation? Researchers sometimes frame the context of their work through small descriptive pieces of context that we might see described in papers, such as the specifics of the classroom, the backgrounds of the students, the demographics of the schools, etc. These can be important for understanding what is able to be accomplished in the place and situation being researched. However, we argue that it is critical to also conceive of context as much larger than simply the details of the "where" and "who" of the research study so that we as researchers can be responsive to the people involved with, and implicated by, the work that we do.

\section{The relevance of context}

Context is defined as the inter-related conditions in which something exists or occurs (http:// www.merriam-webster.com/dictionary/context). Aligned with the perspectives of Gallard Martínez et al., we frame these inter-related conditions as encompassing the situatedness of a given experience for a participant; as connected to their socially, historically, and politically constituted positionality. Through a grounding in dialectical theoretical understandings, our research considers the relationship between agency and structure (e.g., Siry, Wilmes and Haus 2016). The structures of a given situation impact the ways in which a person can, or cannot, take agency. In other words, the contextual aspects of a situation can shape what can actually occur at that time. Context matters. The inter-related conditions that create context (the school, community, home, classroom, subject...) all come together to structure and contour the events that become documented and analyzed through educational research processes. The ways in which we shine a light on context impact what we are able to see, and thus what we are able to understand, and as such, we accept that there is no complete understanding possible. Rather, we can work toward understandings of specific components, to work toward making sense of what we are experiencing, and trying to understand what the participants of our research may be experiencing. In doing so, an important consideration is the perspective that there is no overarching truth per se. "Truths" are "conditioned by the cultures to which we belong and the historical circumstances in which we find ourselves" (Warnke 1987, p. 1). In short, these "truths" are the locally contextualized ways of being that we can try to make sense of through research practice.

Our work is guided by hermeneutics, which we see as the art of understanding, as well as the theory of interpreting. There is a distinct difference between explaining the events that happen, and trying to understand them. Through hermeneutics we can work toward understanding (what Gadamer (1989) has called Verstehen), which is primarily the process of coming to an understanding with others (Verständigung). The hermeneutic circle necessitates that understanding be built up from an understanding of the parts that come together to create the whole. Thus, we can work toward understanding what a given action is, for example, and also try to understand why that action occurs. To do this, one must place 
events within context in order to better understand them. Placing events within the context in which they occur is quite a complex process. Through this process, one can emerge with research that is sensitive to context, and then engage in hermeneutic interpretation to make sense of it through our own perspectives and also through the contextualized presentation of the experience.

\section{Contextually responsive research designs}

Research designs and interpretations are shaped by the theoretical stance of the researcher, and by the theoretical perspectives they bring to their work. Our own research projects are guided by critical theoretical perspectives and the associated epistemological, ontological, and axiological positionings (e.g., Kincheloe 2005). A methodological grounding in hermeneutics supports our focus on working toward the fusing of horizons, and moving from part to whole, in a contextually responsive manner (Gadamer 1989). Gaining new perspectives on a specific context can mediate the connections made to other places and spaces, which is supported by layering diverse methods and theories together in our research. The work that we do is multi-theoretical and multi-method, and we have found bricolage to be an important tool for highlighting context, as well as for highlighting complexity (Kincheloe 2005).

There are hazards in not paying attention to contextually mitigating factors, as Gallard Martínez et al. discuss, as researchers run the risk of simply reproducing the status quo through studies that are not attuned to the immense complexities of social interaction and the historical-political-social-cultural ways in which people are positioned within a particular setting. However, we continually ask, can we ever see, know, or understand another's complexities and realities? We believe that there is value in repeatedly asking this question, and in reflecting on it to recognize that it is never possible to fully understand. Thus there is value in turning our attention toward trying to understand CMFs together with participants. With this understanding of the complexities of working toward contextually responsive research designs, we now turn to look at how we work to employ these in our research.

\section{The context for our work}

Our research is situated in Luxembourg, a country with an immigrant population of almost 50\% and more than 170 different nationalities represented (STATEC 2018). Over the past 25 years, Luxembourg has experienced "the highest sustained inflow of immigrants with respect to the total population" in Europe (Eurydice 2004). The diversity in the country is also represented in the schools, with $46 \%$ of students being non-Luxembourgish nationals (MENJE 2019). Our national public primary school system is trilingual, with different subjects being instructed in one of the three languages of the curriculum; French, German, or Luxembourgish. Many classrooms have children that draw upon a multitude of communicative resources, while also learning the langauges of instruction. Within this wonderfully complex system, we have been conducting research into children's interactions in primary school science investigations (e.g., Wilmes and Siry 2018). 


\section{The complexities of a tri-lingual school system}

Science at the primary level in Luxembourg is to be taught in German, and an important consideration in trying to understand children's interactions in science is that most of the students we work with do not come to school with proficiency in German. The research we are doing in multilingual classrooms within this national context intends to better situate students' language capacities as resources for learning science, and not as deficits to be overcome (e.g., Siry 2011). It is not a simple task to bring together children with different languages and attempt to instruct them in one language, or, as in the case in our tri-lingual school system, in three languages. Olga, a fourth grader from a study we have undertaken, detailed for us the multilingual ways in which she works in small groups in science with her peers, as she explains:

...we have to choose a language, because when Thomas speaks, his mother tongue is French, and Nicola's is Montenegrin. So, we speak Luxembourgish and German, but Thomas speaks a funny German and Luxembourgish ... French he speaks very well. If I was alone in a group with him I would have chosen French.

Olga was born in Luxembourg. Her mother is German and her father is French. She speaks three languages at home; Luxembourgish, German, and French. These three languages are the official languages of instruction in Luxembourg. She is actually not typical of most children in the schools in Luxembourg City, as they often speak a language other than these three at home (e.g., Portuguese, Mandarin, Polish...the list is long). Their languages are resources that these children draw on in their interactions with their peers. We have seen and heard children move between languages seamlessly as needed in both informal contexts like the school grounds and formal contexts like the classroom, yet such translanguaging is not typically sanctioned in our schools. An encounter with a teacher underscored the dilemma presented by the diversity of language proficiencies in classrooms, as she told us that,

The children know the names of all the things we are talking about, but not always in the language they are supposed to know them in. They can speak a lot of languages, but not with fluency across them, especially in subjects like science.

This highlights a perspective that predominantly drives primary science instruction, that students ought to be "fluent" across the sanctioned languages of the curriculum. As we mentioned, science in the national curriculum is to be instructed in German, yet many children do not come to the Luxembourgish primary school system with fluency in German, and as such, may not to be able to name the phenomena they are observing in German. In reflecting upon the contributions of Gallard Martínez et al.'s work, we can better understand the factors that come together to position the children and their teachers, often within a space of tension, one that lies between the ways in which culturally and linguistically diverse children express themselves, and policies that require students express themselves in one language at a time.

\section{Participatory research approaches can highlight CMFs}

In our research, we adopt participatory methods for working with participants as we seek to find ways to work towards equitable, participatory research practices that are responsive to local needs. In this section, we highlight methodologies that allow for examining the many 
cultural and communicative resources children and teachers bring to primary school science investigations. We strive to create structures for working with participants that are built upon collectively constructing goals and actions, based on individual perspectives and needs, yet we are cognizant of the fact that once we begin to try to represent the contextual social/cultural/ historical/political complexities of these multilingual classrooms by writing about the individual students such as Olga, the complexity becomes greatly reduced. Further, in combining children into language groups and referring to them by the national languages they speak (the Polish speaker, the Portuguese speaker, etc.) the essence of the individual is attached to a large nationality-bound identity, nuances related to more microlevel identity are reduced, and are often lost. Echoing Hannah Arendt, we are acutely aware that "the moment we want to say who somebody is, our very vocabulary leads us astray into saying what he is" (1958, p. 181).

We have conducted research examining the work of Olga and her classmates (e.g., Wilmes and Siry 2018, 2020), which has provided a closer look at the microlevel of the classroom and school, and how Olga's teacher and her classmates were positioned to learn science through instructional structures that mediated their taking agency (Siry, Wilmes and Haus 2016). At one point in our work together in the classroom, Olga's teacher, with whom we were collaborating closely through our research, was overheard saying, now we need to go back to real learning. This moved us toward a moment of radical understanding of how through our work in the classroom we could help support the use of this more equitable science instruction, but there were other CMFs of differing grain sizes (meso-school and macro-national curriculum, etc.) that would cause constraints. This underscored the value and necessity of our use of participatory research approaches such as coteaching (Roth and Tobin 2004) and co-autoethnography with teachers that work within our national system (Wilmes, te Heesen, Siry, Kneip and Heinericy 2018); methodologies that allow us to not only work within the system, and learn about the system, but to also question the system from multiple perspectives. Learning communities operate at the intersections of numerous interacting systems, and recontextualizing learning to unpack difference and work across contextual boundaries can support possibilities for change (Walton et al. 2019). It has been through the use of participatory, dialogic, approaches, and the multiple perspectives on CMFs that they afford us in our collaborative research, that we have been able to imagine new possibilities for science instruction in our trilingual national context.

\section{Imagining the possibilities}

The role of imagination is not to resolve, not to point the way, not to improve. It is to awaken, to disclose the ordinarily unseen, unheard, and unexpected (Greene 1995, p. 28).

Imagination creates a space, an opening for rethinking and reimagining that which is not present, but that which could be. Imagination is central for envisioning how to work within (and around) rigid institutional structures that require science be taught in one way, and in one language, to find approaches to create spaces for listening and working toward new ways of situating science as a subject at the primary level. There is a reductionism that can happen to science as a content area, once we try to compartmentalize facts in bitesize ways that might seem "appropriate" for young children. What would happen if we instead begin with the children's perspectives, languages, and experiences? How can we open pathways so that there is dialogue across difference, and that difference becomes the point of interacting, listening, and valuing? 
Imagining becomes important for the children as well, as it also extends to valuing the imaginative ways in which children engage in science, and in representing phenomena. Can we imagine spaces for teachers and students to push back on the notions of "one right answer" that becomes a stopping point for the generation of new questions and investigations? "Difference generates beings in continuous, unique and unpredictable encounters. As I rely on the other to generate me, the difference of the other then, becomes positive" (Rautio 2013, p. 398). In coming together across difference (different ideas on phenomena, different languages, etc.) we may find the generative spaces in which science understandings can be produced. This requires trust in the value of difference, and trust in the other. Returning to fourth grader Olga, she continued our conversation by clarifying the dynamics of the children's multilingual interactions:

Sometimes the language simply switches. For example, in Nicola's group it was always Luxembourgish, but then it was German, French, Luxembourgish, German...

Nicola would say 'now stop with the French speaking, I can't understand any more'.

The complexity that Olga describes could be considered overwhelming. But what we observed, time and time again, with Olga and her classmates, and in many other classrooms operating at this level of communicative complexity, was that the students work through and beyond this complexity of difference. They find ways to access diverse communicative resources, and to not position difference as a stopping point. They carry on in creative ways to work together and to communicate with one another and their teachers in ways that make space for difference, and that honor plurality as a resource. We take inspiration in this. The students like Olga are showing us how to approach difference as possibility, and to remain open to creativity in moments of difference in ways that lead toward possibility. In our research, we have worked with the same spirit of possibility. Even though it may be scary, as Gallard Martínez et al. (this issue) point out, this stance "necessitates a researcher challenging, unpacking and repacking their ontological-epistemological-axiological stances." We must unpack our own positions as researchers, in order to push ourselves to imagine what could be both within our research and in teaching science.

\section{Valuing differences}

Our research has revealed that the children we are working with navigate multilingual interactions in fluid, flexible, powerful ways, as they draw on the resources available to them, including languages, gestures, and materials (e.g. Siry and Gorges 2019). However, this multilingual school system requires science proficiency in one language only, and as a result children often have difficulties in drawing on the many resources they actually have at hand. Further, in a system that defines science proficiency as fact-based, children are not able to utilize the processes they bring to the doing of science. Returning to Maxine Greene's quote, the role of imagination is to awaken and disclose that which we have not seen yet. She reminds us to search for the interstices and to find ways to cultivate a "wideawakeness"; and it is precisely this wide-awakeness that we seek to facilitate between students and teachers and researchers, through participatory, dialogic practices.

We draw on multiple qualitative methodologies in our research projects, and use sociocultural theories to make sense of ways in which science teaching and learning occur in classroom contexts. By layering theories together, we emerge with multi-theoretical approaches which allow us to draw on different inter-related theories to better understand 
the complexities of learning and teaching processes around science. The dialectical relationship between structure and agency (Sewell 1999) is particularly salient to the work we do, as we examine students' agency, and consider how the structures in classrooms mediate the ways in which children engage in science investigations.

\section{Considerations of context as researchers in cultural studies}

"We are situated in history and historically conditioned. This means that our conception of rationality is subject to the limitations of the historical experiences we have inherited" (Warnke 1987, p. x). Historical/social/political/interpersonal/cultural/epistemological contexts... all of these are important in our interpretations. Needless to say, it would not be possible to engage in research that is completely adapted to contextual understandings on all these levels and through all these lenses. However, if there are great discontinuities between contexts, deficits can emerge (Nieto 2001). As researchers, we can attempt to interpret what we see, hear, or read, but when we are confronted with material that is not clear or even contradictory to what we have been experiencing, we may turn to context. But what would happen if we always begin by situating our participants and our data resources within the context in which they are positioned?

Research is a way of making meaning, of understanding. In the hermeneutic tradition, it bridges part to whole. A central part of this hermeneutic process is considering the meanings that are given to actions and moments by those who are participating in them, in short, to remain open to the meanings of others, which often implies situating the meanings in relationship to our own. Some have chosen to use the metaphor of an onion in working toward contextualized research (e.g., MacNaughton, Rolfe and Siraj-Blatchford 2010), as there are multiple layered meanings that are to be uncovered, and these are positioned by the differing viewpoints and experiences of our participants. With a grounding in critical theoretical perspectives, it is central to situate work within an understanding and an appreciation of difference and the CMFs that relate to this difference. The lenses and foundations we bring to research require us to acknowledge context. However, we believe that our ethical perspectives oblige us to not only acknowledge it, but to insist on having a responsibility to highlight and unpack the complex role of context in our interactions as teachers and learners.

\section{Concluding thoughts}

Education in and of itself is a complex system, in which the relationships between systems, research, and reform initiatives become central. Regardless of whether a researcher is working toward understanding an individual's experiences, those of a group of people, or an educational system on the overall, there is much to be learned from working toward unpacking the contextual complexities of these systems through, as Gallard Martínez et al. (this issue) explain, "processes of zooming-in through cycles of radical doubt and complex systems thinking, in attempts to mature an understanding of contextual landscapes." In our work, we seek to find a way to open up spaces for the welcoming of multiple realities, all existing together in the complexities of multilingual primary classrooms. As we write these words, we are aware of how cliché and even naive this might sound. However, we believe that as a field we need to find ways to highlight the contextualized experiences of 
participants within the collective institutionalized structures at play in classrooms, and this requires the space and the time for working together with teachers and children to illuminate their different perspectives and experiences. In seeking to do this, participants can work toward seeing each other as "who" and not "what," thus creating an "in-between" (Arendt 1958, p. 182), to move toward recognizing the inherent differences and the value within these differences. We can never fully understand or know another's experiences or understandings, and institutional structures (including teachers' expectations) shape what can happen in classrooms. However, within these structures there is the possibility to find interstices (Greene 1995), and from these we believe we can seek to create the interstitial forms of culture (Tobin 2008) that teachers and students can use to produce and transform science learning interactions. Engaging in face-to-face, open-ended interactions can support moving toward what Schutz (1967, p. 115) has called a "Wirbeziehung" (a we-relationship), as we work together to reflectively create meaning from experiences. To do so, there must be opportunities to come together and support participants in the research process, and through doing so, position them to recognize what is and imagine what could be.

Open Access This article is licensed under a Creative Commons Attribution 4.0 International License, which permits use, sharing, adaptation, distribution and reproduction in any medium or format, as long as you give appropriate credit to the original author(s) and the source, provide a link to the Creative Commons licence, and indicate if changes were made. The images or other third party material in this article are included in the article's Creative Commons licence, unless indicated otherwise in a credit line to the material. If material is not included in the article's Creative Commons licence and your intended use is not permitted by statutory regulation or exceeds the permitted use, you will need to obtain permission directly from the copyright holder. To view a copy of this licence, visit http://creativecommons.org/licenses/by/4.0/.

\section{References}

Arendt, H. (1958). The human condition. Chicago: University of Chicago Press.

Eurydice. (2004). Integrating immigrant children into schools in Europe. Brussels: Eurydice Network.

Gadamer, H. G. (1989). Truth and method (2nd rev. ed.) (J. Weinsheimer \& D.G. Marshall, Trans.). New York: Crossroads.

Greene, M. (1995). Releasing the imagination: Essays on education, the arts, and social change. San Francisco: Jossey Bass.

Kincheloe, J. L. (2005). On to the next level: Continuing the conceptualization of the bricolage. Qualitative Inquiry, 11, 323-350. https://doi.org/10.1177/1077800405275056.

MacNaughton, G., Rolfe, S., \& Siraj-Blatchford, (2010). Doing early childhood research: International perspectives on theory and practice (2nd ed.). New York: Open University Press.

Ministère de l'Éduction nationale, de l'Enfance et de la junesse (MENJE). (2019). Les chiffres clés de l'éducation nationale: Statistiques et indicateurs 2016-2018. Luxembourg. http://www.men.public.lu/ catalogue-publications/fondamental/statistiques-analyses/statistiques-globales/2016-2018/ef-16-17-18. pdf.

Nieto, S. (2001). Language, culture, and teaching: Critical perspectives. New York: Routledge.

Rautio, P. (2013). Children who carry stones in their pockets: On autotelic material practices in everyday life. Children's Geographies, 11(4), 394-408. https://doi.org/10.1080/14733285.2013.812278.

Roth, W. M., \& Tobin, K. (2004). Coteaching: From praxis to theory. Teachers and Teaching, 10(2), 161179. https://doi.org/10.1080/0954025032000188017.

Schutz, A. (1967). The phenomenology of the social world. Evanston: Northwestern University Press.

Sewell, W. H. (1999). The concept(s) of culture. In V. E. Bonnell \& L. Hunt (Eds.), Beyond the cultural turn: New directions in the study of society and culture. Berkeley, CA: University of California Press.

Siry, C. (2011). Exploring the significance of resource-rich views in science education. Cultural Studies of Science Education, 6, 1019-1029. https://doi.org/10.1007/s11422-011-9353-3.

Siry, C., \& Gorges, A. (2019). Young students' diverse resources for meaning making in science: Learning from multilingual contexts. International Journal of Science Education. https://doi.org/10.1080/09500 693.2019.1625495. 
Siry, C., Wilmes, S. E. D., \& Haus, J. M. (2016). Examining children's agency within participatory structures in primary science investigations. Learning, Culture and Social Interaction, 10, 4-16. https://doi. org/10.1016/j.lcsi.2016.01.001.

STATEC (National Institute of Statistics and Economic Studies of the Grand Duchy of Luxembourg). (2018). Evolution of total, Luxembourgish and foreign population 1961-2019. Retrieved from http:// statistiques.public.lu/stat/TableViewer/tableView.aspx?ReportId=12858\&Language=fra\&MainT heme $=2$.

Tobin, K. (2008). In search of new lights: Getting the most from competing perspectives. Cultural Studies of Science Education, 3(2), 227-330. https://doi.org/10.1007/s11422-008-9109-x.

Walton, E., Carrington, S., Saggers, B., Edwards, C., \& Kimani, W. (2019). What matters in learning communities for inclusive education: A cross-case analysis. Professional Development in Education. https ://doi.org/10.1080/19415257.2019.1689525.

Warnke, G. (1987). Gadamer: Hermeneutics, tradition, and reason. Stanford: Stanford University Press.

White, R. (1985). The importance of context in educational research. Research in Science Education, 15(1), 92-102. https://doi.org/10.1007/bf02356530.

Wilmes, S. E. D., \& Siry, C. (2018). Interaction rituals and inquiry-based science instruction: Analysis of student participation in small-group investigations in a multilingual classroom. Science Education, 102(5), 1107-1128. https://doi.org/10.1002/sce.21462.

Wilmes, S. E. D., \& Siry, C. (2020). Science notebooks as interactional spaces in a multilingual classroom: Not just ideas on paper. Journal of Research in Science Teaching. https://doi.org/10.1002/tea.21615.

Wilmes, S. E. D., Te Heesen, K., Siry, C., Kneip, N., \& Heinericy, S. (2018). The role of critical reflexivity in the professional development of professional developers: A co-autoethnographic exploration. Interfaces Científicas, 7(1), 13-24. https://doi.org/10.17564/2316-3828.2018v7n1p13-24.

Publisher's Note Springer Nature remains neutral with regard to jurisdictional claims in published maps and institutional affiliations.

Christina Siry is a professor of learning and instruction at the University of Luxembourg, and her research examines how young children develop and transform their science understandings through multilingual, multi-modal interactions in schools. She has several lines of research that focus on the intertwined areas of science learning and learning to teach science, particularly at the primary and early childhood levels. Together with her research team, she investigates the ways in which plurilingual young children interact with peers, teachers and materials as they engage in science lessons.

Sara E. D. Wilmes is a researcher at the University of Luxembourg in the Institute for Teaching and Learning. She currently works with the SciTeach Project (PI: Christina Siry) to support collaborative teacher education and professional learning for sustained changes in primary science teaching and learning in Luxembourg. Her research explores science education in multilingual contexts and the use of postmodern research methodologies to explore intersections between science learning and diverse communicative resource use. 